\title{
John Searle’s Literary Theory Thoughts of “Fictional” and “Pretended” Speech Acts
}

\author{
Cunjiu Kuang1, a \\ ${ }^{1}$ College of Humanities, Sichuan Agricultural University, Ya’an, Sichuan Province, 625104, China \\ aemail: 476033678@qq.com
}

Keywords: John Searle; “fictional”; “pretended”; speech act; literary thoughts

\begin{abstract}
John Searle has inherited the traditional theory of literary fiction, Wittgenstein’s concepts of "family resemblance” and language games, and Austin’s literary concept of “parasitic", regarded literature, in its essence, as a "fictional”, "pretended" and atypical speech act, and developed his unique literary theory of speech act, which has important theoretical significance and value for contemporary literary theory development.
\end{abstract}

\section{Introduction}

John Rogers Searle (born 31 July 1932) has been universally recognized as the biggest authority in the field of contemporary speech act theory, a master and a figure of myth after J. L. Austin in the field of speech act theory, and among the world's most well-known and influential contemporary philosophers. Searle has extensively discussed modern literary theories, which, however, did not attract much attention in China's literary theory circle until in recent years. In this paper, John Searle's literary theory thoughts of "fictional" and "pretended" speech acts are expounded, calling for attention, in the academic circles, to Seale’s literary thoughts of speech acts.

\section{Literature as a Special Speech Act}

In the late 1960s, when John Searle published his first book, he explicitly noted that, "all linguistic communication involves linguistic acts". In 1975, he stressed again that, "theories of language should be able to deal with any text at all and not just with specially selected examples”. That means, literature is a speech act; reading or writing in a language is to perform an explicit speech act, which is unquestionable for John Searle. By inheriting in his literary essence theory the traditional theory of literary fiction, Wittgenstein's concepts of “family resemblance” and language games, and Austin's literary concept of "parasitic", Searle, based on them, has developed his unique literary theory of pretended performative, covering keywords such as "special, fictional, parasitic, additional, game, pretended performance, atypical”, attracting much attention from the Western literary circle.

Searle started his literary studies with fictional discourses. He, in the first place, regarded literature as a specially selected example of speech act, and critically inherited J. L. Austin's view of treating literature as a "hollow", "non-serious" discourse and "parasitic" upon everyday standard discourses. In his view, fictional discourses are a special game, and "the language game is not on all fours with illocutionary language games, but is parasitic on them”. It is obvious that, Searle's theory of fictional discourse has absorbed Wittgenstein's concept of "language games" as well as Austin's "parasitic" view of literary discourse. To be specific, the peculiarity of fiction literature lies in that it "contains another class of illocutionary acts (writing stories, novels, poems, plays, etc.)”. Compared with standard everyday discourses, "the writer or speaker of fiction has his own repertoire of illocutionary acts which are on all fours with, but in addition to, the standard illocutionary acts of asking questions, making requests, making promises, giving descriptions, and so on". That's to say, fiction literature is to everyday discourses what additional to standard, and parasitic to norm. The view of being "additional” may also be taken as his development of Austin's "parasitic" view. In other words, such 
speech acts as statements, questions, commands, promises, apologies, and gratitude etc in everyday discourses also extensively exist in literary discourses. For instance, assertions are among the most frequently used in literature. At this point, Gérard Genette, a French narratology scholar, held that, a large number of fictional discourses perform serious illocutionary acts by means of "tropics" and Searle's "indirect speech acts". There also exist numerous "directives", "declarations" and "promises" in fictional discourses. In his opinion, "narrative fictions, just like mathematical fictions or any other fiction, may also be an announcement of the meanings of Searle". Further explained, the meanings of words of other language elements in fictional discourses, compared with everyday discourses, have no difference indeed. For Searle, it is because "the utterance acts in fiction are indistinguishable from the utterance acts of serious discourse, and it is for that reason that there is no textual property that will identify a stretch of discourse as a work of fiction”.

Searle believes that, fiction literature is with the characteristic of "pretending". Normally, "the author pretends to perform illocutionary acts by way of actually uttering (writing) sentences"; "pretended illocutions constitute a work of fiction". To be specific, the peculiarity of fiction literature is intensively embodied by characteristics such as "fiction" and "pretending" etc. Searle compared and analyzed the discourses in the novel the Red and the Green written by Iris Murdoch, and in New York Times, and to him, discourses such as statements, assertions and promises in novels do not make any real promise to any proposition. That means, the writer does not make any promise or guarantee for any statement or assertion in novels that it really exist in real life, nor provide any evidence to prove the authenticity of these events. And, as for readers, no one believes that such a person or thing really exist at a certain time or place in real life, and no one would, for that reason, regard the author's making of statement or assertion as an "insincere" act. Based on that, John Searle holds that, fictional literature is a pretended performance without any intent to deceive. That means, the author usually only "pretends" to perform an act, instead of really performing that. "Pretending" may be deceiving or not. In Searle's view, fictional discourses are just such a class of discourse without any intent to deceive. Generally speaking, authors' pretending in such fictional works mainly refer to some "representative" illocutionary acts of pretended performances, instead of some expressive illocutionary acts, such as writing stories, novels, poems, plays, etc, which are main forms of performance among fictional and pretended speech acts. It can be discovered that, representative pretended performance is more obvious than expressive pretended performance.

Searle combines fiction with imagination and expounds the nature of fiction and pretense in literary performative. According to him, fiction is frequently combined with imagination in fictional discourses, which plays a vital role in human society, even though the role of imagination is often underestimated. Nonetheless, in fiction literature, imagination establishes correlations of many fictional discourses. It can be found that, any important fictional works may potentially deliver a "message" or moral, while such a message or moral is indeed the speech acts that the author really wants to express, i.e. the illocutionary force. For example, children's literature often ends with "the moral of the story is ...", and some realist authors also often have serious speech acts, such as some didactic works frequently appearing in Tolstoy's novels, which may be the deep intention that the fictional works really want to convey. Based on that, Searle believes that, in fiction literature, with pretended performance, one may perform a higher order or complex action by performing lower order or less complex actions, and these lower order or less complex actions are constitutive parts of the higher order or complex action, similar to the relationship between an aim and the means or "throwing out a brick to attract a jade". In a pretended hitting in real life, the action of hitting is pretended, but the arm and fist movements, which are constitutive parts of hitting, are real. So is the fictional discourse: the utterance of a simple speech act aims to introduce complex speech acts. This is also somewhat similar to Searle's indirect speech acts, i.e. a speech act is achieved indirectly through another speech act, which can be readily seen in writers' works and readers' reading. As Searle points out, in fiction literature, "the illocutionary act is pretended, but the utterance act is real". The task of literary critics is to find a mechanism to explain how the author "conveys a serious speech act through the performance of the pretended speech acts", "but there is as yet no general theory of the mechanism". 


\section{As an Atypical Speech Act}

The peculiarity of Searle's theory of literary performative lies in that literature is an atypical speech act. He has stressed for times that, literature is a concept of "family resemblance" proposed by Wittgenstein, to which the distinction and boundary between concepts are obscure and continuous, not discrete. These concepts are similar to a family group: the closer they are in kinship, the more central they are in the family, with more typical family characteristics. For example, "birds", as a concept of family resemblance, are often characterized by the ability to fly, twittering and with wings etc, so those like sparrows and swallows are typical birds, and ostriches and penguins, unable to fly, are less typical birds. However, they are all birds, only with the difference in the quantity of bird features. Searle has applied these concepts into the whole process of speech act theory. For example, the more typical and complete the speech acts are, the more styles of everyday discourses or standard discourses they have; the more atypical or marginal the speech acts are, the fewer such features they have. Later, when he remarked on Jonathan Culler's destruction thoughts, he emphasized again that, there is no need in literary theory to exclude conceptual analysis, since no distinction has extremely strict or accurate borders; theoretical analysis, for example, entails more or less practical analysis. He stresses again that, this is an important consensus in analytic philosophy, and the majority of concept distinctions are based on roughly-defined borders, without any exceptionally obvious borders; for example, there are no highly obvious distinctions between being fat and thin, rich and poor, or democratic and autocratic. Searle believes that, this point is vital to literary theory discussion, for such rough distinctions somewhat exist between being literal and metaphorical, serious and non-serious, and fictional and non-fictional. Since the establishment of speech act theory in 1953, it has been constantly claimed that there is no exceptionally strict borders. And this obscurity and open structure of concept can be traced back to its main origin: Wittgenstein's concept of "family resemblance”. To be specific, according to Searle, a typical speech act should consist of four acts: (1) an utterance act, which means the act of uttering or writing down morphemes or sentences; (2) a propositional act, whose typical form is that a sentence or a paragraph etc normally includes the reference and the predication; (3) an illocutionary act, including such types as statements, inquiries, orders, thanks, and guarantees, and (4) a perlocutionary act, i.e. the influence and effect of illocutionary act etc. If the speaker or the writer simultaneously performs the utterance, propositional, illocutionary acts etc., then he/she is typically performing a speech act. It can be seen that, fictional discourses and literature, to Searle, are some atypical speech acts under the concept of family resemblance. Fictional discourses and everyday discourses, for example, are both typical and atypical members under the concept of family resemblance, and their relationship is continuous, without any strikingly clear border. Therefore, the distinction between fictional works and literary works is no longer absolute. Fictional works, like comic books and jokes, are definitely not literary works. Moreover, fiction is not exclusive to literary works, and not all literary works are fictional; literary works contain real factors; not all everyday discourses are real, and they also contain fictional elements. In his view, "a work of fiction need not consist entirely of, and in general will not consist entirely of, fictional discourse”. One example is the starting sentence in Tolstoy's Anna Karenina "Happy families are all happy in the same way, unhappy families unhappy in their separate, different ways", which, despite a fictional discourse, is a "serious" utterance. Nabokov adapted it into "All happy families are more or less dissimilar; all unhappy ones more or less alike”, which seems to be a misquotation and yet still remains a serious utterance. Thus, it is not realistic to strictly distinguish serious discourse from non-serious discourse and fictional discourse from literary discourse. Searle distinguishes fictional discourse from literary discourse with the concept of family resemblance, adding to it a new connotation of literary essence theory. Subsequently, Searle makes a distinction of the following concept pairs with "family resemblance": everyday discourse/fictional discourse; fictional works/literary works; serious discourse/non-serious discourse. Habermas affirms Searle's conceptual distinction for the speech act theory, labeling it as one of Searle's most important contributions. Genette also believes that, it seems smarter for Searle to describe the relationship as one of convergence. 
Searle's "pretended” performative and regarding fictional, parasitic, additional and atypical natures and features as literary ones represent an early literary essence view of speech act. Contemporary with Searle's, Richard Ohmann's theory of “quasi-speech acts”, Martin Steinmann's view of "pretended imitation speech acts", and Barbara Smith's view of "representative speech acts" also inherited Austin's literary "parasitic” view. Later, however, such parasitic, fictional, imitation and additional literary views were gradually deconstructed by emerging deconstructivism. Pratt, Fish, Derrida, Deman, Miller, Keller, and Butler, amongst others, attempted to obscure the borders between everyday discourse and fictional discourse, regarding literary discourse and everyday discourse as discourses with the same performative function, which, in fact, is somewhat similar to Searle's treatment of fictional discourse with Wittgenstein's concept of “family resemblance”. Searle holds that, the mistake in Derrida's repeated différance view lies in that, he ignores the common sense that there is no strict border or distinction between concepts, and that he even wrongly assumed that, only highly strict or accurate distinction can be regarded as conceptual distinction. Searle makes a vivid metaphor: what Derrida pursues is a "crystal” pure conceptual distinction, which actually does not exist at all. Searle criticizes that, Derrida's view of intentional states is similar to that, with a tendency of absolutization; Derrida calls the intentional states "self-existence of thoughts". Therefore, Searle holds that, Derrida's deconstruction of "binary" patterns, such as everyday discourse and literary discourse, fictional and non-fictional, context and meaning, serious and non-serious, standard and additional, does not reflect the reality. Personally, the author believes that, it is highly likely that this is a critique strategy of deconstructivism, and it was not that they did not notice Searle's notion of "family resemblance", but they purposefully ignored it.

Searle further holds that, "literature" is the "name of attitudes" taken towards a stretch of discourse. The so-called "name of attitudes" demonstrates an indicative mark as well as an intentional expression. On the one hand, as an indicative mark, "literature" is only for the convenience of memorizing or calling, without many other meanings. Searle has reiterated that, the names of "literature" and "fiction" are not stipulation on the essential attributes of these discourses, so there is no need to excessively focus on the concepts of literature and fiction. The issue of serious discourse, for example, is faced by both the real world and the fictitious world. An example may be "he is the son of a blacksmith", which, in the real world, is both literal and serious; in the fictitious world, it is literal, but is non-serious. So is metaphor. The metaphor in everyday discourse is "non-literal", but may be "serious"; in fictional scenes, the metaphor may be "non-serious" and, more likely, "non-literal". On the other hand, as a "name of attitudes", literature is clearly intentional. Searle believes that, whether or not it is fiction is for the author to decide; that's to say, the author decides the realness of characters and events in the fictitious world.

Besides, Searle has analyzed, in details, the pretended speech acts in novels and plays. In his view, in person narratives in novels, either first-person or third-person narrative, the author pretends to make certain assertions or acts. So are dramatic texts. Nevertheless, playwrights do not often pretend to act inside, but pretend to perform through character roles in actual performances. He points out that, "A fictional story is a pretended representation of a state of affairs; but a play, that is, a play as performed, is not a pretended representation of a state of affairs but the pretended state of affairs itself, the actors pretend to be the characters". It can be discovered that, Searle's analyses are quite fine and delicate. For him, the playwright is rather like writing "a recipe for pretense", and his work is to describe the actor's pretended roles in the play and give pretense directions to actors.

\section{Conclusion}

John Searle has introduced the speech act theory into literature and established the fictional and pretended literary performative theory, whose theoretical significance and value are self-evident. A Chinese scholar, Wang Jianxiang, for instance, holds that, Searle’s positioning of literary fictional discourse has provided philosophical bases and theoretical source for the literary theory to walk out from formalist literary theory and into reality. Zhang Yu also points out that, “Ohmann's and Searle’s theories of literary speech act are representatives of the early application of speech act theory to 
literary studies in the critic circle”. Wang Feng points out that, Searle "has made quite fantastic and thorough analyses of the illocutionary act of fiction, and proposed some constructive understandings of the complex relationship between literature and fiction”. Feng Qing also remarks that, Searle's speech act theory and his expounding of literary topics have provided highly exquisite theoretical support. Common reviewers have noticed the fictional and pretense aspects of Searle's literary performative theory, but have failed to see its atypical aspect. According to the Chinese scholar Zhang Yu, on Austin's exclusion of literary discourse from serious discourse, Searle has taken a compromised strategy, i.e. conditionally accepting literature as a special speech act and conditionally applying the speech act theory into literary studies. Indeed, Searle's literary pretending performative was put forward under a special historical background, which has inherited Austin's literary "parasitic" view and learned from Wittgenstein's notions of "family resemblance" and "typicality" and even the research strategy of Chomsky's transformational-generative grammar. Compared with typical, standard and normal texts in everyday discourse, literature is a fictional, parasitic, additional and pretended special text. In Searle's view, literature is a special form of standard speech act framework, which controls the generation of special texts through settings of standard text parameters or output and input conditions. John Searle's speech act theory focuses on three fields: mind, language and society, while his literary performative theory has inexplicitly combined mind, language and society into his study, such as his discussion about the author's intention, fictitious world and real world reference.

\section{References}

[1] Searle, J. R. Speech Acts: An Essay in the Philosophy of Language [M]. Cambridge: Cambridge University Press, 1969: 16.

[2] Searle, J. R. The Logical Status of Fictional Discourse [J]. New Literary History 6, 1974, 5: 319-32.

[3] Wittgenstein, L. Philosophical Investigations [M]. Oxford: Wiley-Blackwell, 2009: 48-54. 